\title{
MEDICAL MALPRACTICE, IMPERFECT INFORMATION, AND THE CONTRACTUAL FOUNDATION FOR MEDICAL SERVICES
}

\author{
Richard A. EPSTEIN*
}

I

INTRODUCTION

The past generation has witnessed both an expansion of medical malpractice liability and a transformation in the delivery of health care services, especially through the growth of health maintenance organizations (HMO's) and other organized health plans. These two developments are not unrelated and considering them together provides some guidance to the reform of the law of medical malpractice. This article addresses the joint significance of these parallel developments in liability and industry structure.

In order to make the connections explicit, the article is divided into three sections. The first section explains why requiring medical practitioners to adhere to professional custom and to obtain patients' informed consent to treatment is an effective legal response to the problem of imperfect information; it also suggests, however, that tort doctrine embodying these requirements should allow providers and patients to vary these and other requirements by private agreement. The second section explores the probable allocation of risks in a regime-unlike the present one-in which the parties could freely contract about liability for medical malpractice. The third section examines the relative abilities of fee-for-service providers and HMO's to respond to the opportunities and pitfalls of a regime allowing contractual allocation of risk by contract.

\section{TORT LAW'S RESPONSES TO IMPERFECT INFORMATION}

The tort law governing medical malpractice is a form of judicial regulation that private parties generally cannot vary by contract.' The matter might

Copyright $(\mathcal{1} 1986$ by Law and Contemporary Problems

* James Parker Hall Professor of Law, University of Chicago.

1. See, e.g., Tunkl v. Regents of Univ. of Cal., 60 Cal. 2d 92, 383 P.2d 441, 32 Cal. Rptr. 33 (1963). Tunkl is discussed at length in Robinson, Rethinking the Allocation of Medical Malpractice Risks Between Patients and Providers, Law \& Contemp. Probs., Spring 1986, at 173, 184-95. I have previously dealt with many of the basic issues in Epstein, Medical Malpractice: The Case for Contract, 1 AM. B. Found. Research J. 87 (1976), and Epstein, Contracting Out of the Medical Malpractice Crisis, 20 PersP. BIOLOGY \& MED. 228 (1977). 
seem to be inconsequential, because the law of negligence requires only that the physician exercise reasonable care under the circumstances. ${ }^{2}$ Yet this bland generalization does more to mislead than to inform, for behind the basic negligence principle lurks a complex set of problematical inquiries: What is the applicable standard of care? How is it set in a given case? Does it vary by specialty, region, or circumstances? How does the standard apply in informed consent cases? What happens when specialists may be needed but are not called? How is the causal connection between the breach and the injury established? For what items of loss are damages allowed? And how are these computed? Answers to each of these questions are currently prescribed by law, mostly by judge-made law. In the current political environment, most efforts to change these rules are targeted at legislatures.

Preoccupation with legislative reforms of malpractice law works to obscure the initial question, which must be why the law seeks to regulate the physician/patient relationship at all. Here, the argument against judicial or legislative specification of duties and rights runs as follows: Where parties stand in a consensual, face-to-face relationship with each other and their actions do not affect nonconsenting third parties, they should have the right to establish the terms that work to their mutual benefit. The physician owns his services, the patient his body and his capital. The two can work together to organize an exchange on mutually acceptable terms, so that each obtains something more valuable than he surrenders. Medical care may be important, but the "special" characteristics of the services involved do not require special legal institutions even if they do require well considered contracts. In short, one might contend, the usual arguments for voluntary markets prevail.

The major objection to this position is that regulation is needed to overcome the enormous information gap between the provider and the consumer of medical services. ${ }^{3}$ In part, the argument is that such regulation reduces the possibility of fraud or of strategic nondisclosure of the physician's lack of professional skill or commitment. Yet these concerns could be met by requiring simple disclosure in the contract of the physician's basic undertaking. For example, an agreement might state that "the standard of malpractice under this contract is the care ordinarily and customarily exercised by providers in this specialty in this locale." Because the parties could thus easily define the provider's commitment, any argument for foreclosing the possibility of mutual gain from contract must go beyond the need to prevent fraud. It must also embrace the concern that the consumer's information on the specific care being received is imperfect or incomplete.

2. For an extended discussion, see Epstein, Medical Malpractice: Its Cause and Cure, in ThE Economics of Medical Malpractice 245 (S. Rottenberg ed. 1978).

3. It seems clear that regulation is not warranted to control harms to third parties. There is no contract to shoot a third party, to pollute a public river, to suborn a jury, or to rig prices. The contract between physician and patient is, at least from the standpoint of externalities, no different from the standard contract for sale, hire, or employment. There is no systematic external loss to offset the joint gains by the parties. 
Direct regulation, it is said, now becomes thinkable as a vehicle to prevent consumers from making medical error.

The hard question is what can be done to handle the problem of imperfect information once it is identified. The doctrine of informed consent reflects a judicial demand for the transfer of information, intended to alleviate the lack of information about particular procedures in individual cases. The informed consent requirement is fitful at best, however, and can work only to compel disclosure of the most salient possible consequences of standard practice, such as ordinary side effects, the major treatment risks, possible permanent disabilities, and the period of rehabilitation. Informed consent thus in no way guarantees a parity of information between the parties, and it certainly cannot enable a patient to evaluate the quality of the physician or to ponder all the technical choices made during diagnosis and therapy. The pressure to find other ways to overcome the information gap should therefore be strong because most consumers will prefer physicians who take cost-justified, systematic steps to reduce their uncertainty. This view of consumer ignorance does not justify imposing insuperable legal obstacles to the formation of private contracts. Such ignorance is simply one of the basic features of the human condition to which a well drafted medical contract should respond.

In practice, one simple strategy has in fact handled much of the information problem associated with remote medical contingencies. In medical malpractice cases, professional custom within the medical region or specialty is generally looked to in defining the applicable standard of care. This standard may be viewed as a contractual standard because it is almost certainly the same standard that the parties would choose for themselves. It has been generally accepted in medical transactions and has rarely been varied by parties attempting to contract for a different standard, either before or after the modern expansion of malpractice liability.

At first glance, the custom standard looks naive, especially when compared to the more complicated substantive rules incorporating explicit cost/benefit tests that some writers have proposed. ${ }^{4}$ But, far from being simple-minded, the customary practice rule has the great virtue, in addition to its administrative efficiency, of obviating the need for initially transferring excessive quantities of information from provider to patient. Any serious medical case involves a myriad of choices. Even if patients could understand the details of the possible treatments, any detailed disclosure must necessarily cover events that are most unlikely to occur in the individual case. Even the most conscientious physician could not disclose critical risks that were discovered only after surgery or treatment had begun. It is too late to turn back and too awkward to negotiate any revision of the agreement on medical treatment. ${ }^{5}$ Full disclosure of all possibilities and nuances in advance is well

4. For a defense of the cost/benefit formula, see Schwartz \& Komesar, Doctors, Damages and Deterrence: An Economic View of Medical Malpractice, 298 NEw ENG. J. MED. 1282 (1978).

5. The standard consent form has the following provision, which in part copes with the issue: "I consent to the performance of operations and procedures in addition to or different from those 
understood to be too costly to be practical; such disclosure would also run the risk of providing unnecessary information and of creating psychological overload as the constant litany of what could go wrong overwhelms any explicit assurance that these catastrophes are low-probability events.

Custom bridges the information gap, however. An agreement stating simply that, for low-probability events, the physician agrees to follow the standards of the profession spares the patient from having to be educated on all the nuances and details of medical treatment. Large amounts of information are, in effect, transmitted in a few words, and costly and detailed disclosures about remote contingencies become unnecessary. In addition, once any given contingency does materialize, then custom allows any resulting dispute to be resolved by recourse to a standard that was not set by the individual physician before the fact and that cannot be manipulated by him after the fact. A public body of information is available as a source of standards to resolve the dispute, and the patient can have recourse to a lawyer and expert witnesses who can focus on the medical details of the case as it actually developed. Parity in information, required to try the lawsuit, is now possible because of the plan adopted at the creation of the physician/patient relationship.

The customary standard may not be perfect, but it is far more reliable than any case-by-case cost/benefit alternative, which would give less information to the patient up front and would create opportunities for greater controversy after the fact of an injury. Open-ended cost/benefit analyses have the vice that they tolerate error rates so high that it is always possible to dispute (after the fact) the appropriateness of any given practice. Even in their simplest variations, the three relevant decisional variables are the expected loss, $L$, the probability of loss, $P$, and the burden of precaution, $B: B$ is greater than, less than, or equal to $P L$. If estimates of each element might vary by as much as a factor of ten, then in combination the disputed standard could vary by a factor of a thousand. ${ }^{6}$ The problem of imperfect information is not solved by the use of a cost/benefit standard, especially if the law also blocks contractual responses that do respond to the problem.

The virtues of tort law's custom standard notwithstanding, imperfect information should not be deemed to preclude contractual respecification of the parties' rights and responsibilities in medical transactions. When parties know that information is incomplete, their information needs and demands will shape the form of the transaction in such a way that each can use the information available to him but is protected against the other party's

now contemplated, whether or not arising from presently unforeseen conditions, which the abovenamed doctor or his associates or assistants may consider necessary or desirable in the course of the operation." R. Morris \& A. Moritz, Doctor and Patient and the LaW 170 (5th ed. 1971).

6. The same issue arises when cost/benefit formulas are used in products liability law, especially in design defect and warning cases. These standards are there subject to the same criticism. See R. Epstein, Modern Products Liability Law 36-48, 68-1 18 (1980). 
informational advantage. ${ }^{7}$ The argument is not that private contracts are perfect, but only that they are likely to be better than any regulatory substitute. Regulators, too, must confront information deficits-on such things as the actual circumstances and the parties' expectations and preferences-and they often incur high administrative costs in seeking to overcome them.

The courts' hostility toward all private contracts regulating the risk of medical injuries has an important hidden cost, for it cuts off information about the soundness of present legal rules and institutions, including not only the seemingly efficient customary practice rule but also the law's many other procedural and substantive requirements. There has been no experimentation with alternative contract terms, no competition between suppliers of medical care over different risk-allocation arrangements, and no opportunity for consumers to diversify and pool their risks. A government monopoly over the specification of contract terms in medical transactions, moreover, does not erode over time like other monopolies. As long as it exists, there is little hope of ever gaining hands-on knowledge about how medical relationships can be altered to the mutual advantage of both providers and patients.

\section{III}

\section{Speculations About Contracting Over Risks}

Without the ability to observe actual medical service contracts, it is necessary to rely upon general theory to estimate how private contracts allocate risk. Here, one can think of three distinct subjects that such contracts might address. Two of the subjects, liability and damages, are substantive; the third, the choice of a forum for resolving disputes, concerns procedure.

In the absence of direct evidence, the inquiry here is aided by an historical comparison to contractual responses to industrial accidents in the late nineteenth century. ${ }^{8}$ At common law, an employer's liability for an accident turned on its negligence in supplying the workplace and equipment, and on the contributory negligence of and assumption of risk by the injured worker. The measure of damages included pain and suffering, medical expenses, and economic loss. Typically, the suits were tried in ordinary courts. The prevailing legal rules were subject to repeated academic and political attacks on familiar grounds: the cost of their operation, the uncertainty of their

7. The same arguments can be made in employment contexts, where one reason for the durability of contracts at will is that neither side has strong information about how the other side will behave. The at will arrangement allows each side to withdraw when the pay-off under the agreement is below expectations. The standard also makes it clear that termination is not a breach, at least in the vast number of cases. The contrast between the at will arrangement and the for-cause dismissal standards in employment cases are the analogues to customary care and cost/benefit standards in medical malpractice cases. For the author's views on the contract at will, see Epstein, In Defense of the Contract at Will, 51 U. CHI. L. Rev. 947 (1984).

8. See Epstein, The Historical Origins and Economic Structure of the Workers' Compensation Laws, 16 GA. L. REv. 775 (1982), for an account of the movement. 
outcome, and their complex incentive effects. ${ }^{9}$ These defects were well understood-and not only by the critics of the system. The available evidence suggests that many firms and workers, especially in dangerous employments, were of the same general view. As a consequence, they adopted systems that anticipated the general features of the mandatory workers' compensation statutes that were introduced in 1897 in England ${ }^{10}$ and early in the twentieth century in this country.

On each of the three points noted, the contracts governing industrial accidents that antedated legislated workers' compensation afford useful clues to how contracts for the delivery of medical services might be structured to allocate accident risks and resolve disputes concerning them. The following discussion draws in part on that experience.

\section{A. Liability}

For reasons that have been explored above, it seems unlikely that any consensual arrangement would adopt the complex cost/benefit tests for negligence that have been proposed by some reformers. Another option is strict or no-fault liability, which was embraced in workers' compensation arrangements. But if those contracts and that experience are any guide, then it must be asked why there has been no comparable move to strict liability in the medical area, as under proposed systems of medical no-fault insurance. ${ }^{11}$ The answer has two parts:

First, the customary care standard is, in one sense, already a strict liability standard. Where there is compliance, the defendant is generally safe. Where there is inadvertent noncompliance with the standard, neither ignorance nor good faith is a defense because the standard is external to the individual actor. Lest the language of negligence mislead, medical malpractice rules do not penalize all "below-average" physicians in the community, no matter how high the prevailing standard. All physicians can simultaneously adhere to 'customary practice, even if all cannot be average or better in ability. (So, too, all physicians could agree to use their best efforts, even if these differ from physician to physician.) Only physicians who do not meet customary standards are subject to strict liability-but only for providing the inferior level of care, not for their simple inability to achieve the desired outcome.

Second, strict liability does not and cannot mean comprehensive coverage of all injuries. Thus, when a worker dies of a heart attack while on the job, ${ }^{12}$

9. See, e.g., 1 T. Shearman \& A. Redfield, Negligence at v, vii (5th ed. 1898); Thompson, Under What Circumstances a Servant Accepts the Risk of His Employment, 31 AM. L. REv. 82, 85-86 (1897).

10. Workmen's Compensation Act, 1897, 60 \& 61 Vict., ch. 37.

11. See, e.g., Havighurst, Medical Adversity Insurance-Has Its Time Come?, 1975 DukE L.J. 1233; Havighurst \& Tancredi, Medical Adversity Insurance-A No-fault Approach to Medical Malpractice and Quality Assurance, 613 INs. L.J. 69 (1974). The practicality of these proposals has been questioned. See Calabresi, The Problem of Malpractice-Trying to Round Out the Circle, in The Economics of Medical Malpractice 233 (S. Rottenberg ed. 1978); Epstein, supra note 2, at 245, 257-67.

12. "The workers' compensation law does not provide compensation for a person afflicted by an illness or disease not caused or aggravated by his work or working conditions." Kostomo v. Marquette Iron Co., 405 Mich. 105, 116, 274 N.W.2d 411, 415 (1979). 
workers' compensation is usually denied. Although the death may have occurred in the course of employment, it did not arise out of the employment in a causal sense. The heart attack may have been attributable to biological predisposition or degeneration, to personal stress, to bad habits, or to diet. Similarly, a poor result of medical treatment may not be attributable to the level of care received.

This same distinction is more or less captured by the customary care standard in medical malpractice cases, which enables the legal system roughly to identify losses resulting from the medical treatment and not from independent causes. The matter is somewhat complicated because patients often assume medical risks in order to forestall greater risks of illness or disease. Yet perverse incentives are created if these treatment losses are routinely charged to the health care provider. A patient facing a ninety percent chance of death from disease is better off (even after costs of treatment are factored in) in receiving a treatment with a success rate of somewhat greater than ten percent. If a success rate above ten percent were obtainable, then in a voluntary market a patient would accept treatment without demanding monetary compensation for all unfortunate outcomes. Ex ante, he would still be better off by an amount proportionate to his increased chances of survival. The proposed medical no-fault plans have never gotten off the ground precisely because their comprehensive compensation criteria do not give the physician credit against liability for these deaths or injuries that would otherwise be brought on by natural causes. Health care providers are not in a good position to supply the large component of pure high-risk life insurance that every no-fault system necessarily contains. The medical nofault system is simply not a likely candidate for private adoption.

In the last analysis, customary practice appears still to be the most practical and efficient standard for use in prescribing a physician's duty-both in tort doctrine and in private contracts. Better than any other standard for defining compensable losses, it draws a line analogous to that in workers' compensation between work-related and non-work-related injuries. ${ }^{13}$ In addition to providing a reasonably objective standard that can be administered at a reasonable (though far from negligible) cost, ${ }^{14}$ the custom standard reveals the mutual benefit to patient and provider from the transaction. In exchange for the fee paid, the patient receives some reduction in the risk of an adverse health result. In effect, he trades a dangerous condition for a less dangerous procedure and some protection against inferior medical treatment.

13. See, for example, Henderson, Should Workmen's Compensation Be Extended to Nonoccupational Injuries, 48 TEx. L. REv. 117 (1968), which, in advocating the social insurance approach, ignores the powerful allocative arguments for keeping the arising-under and scope-of-employment limitations.

14. A similar problem arises in products liability cases where the lack of privity between manufacturer and user means that contract devices cannot be used to regulate the insurance component of the transaction. For a critique of the default rules now in place, see Epstein, Products Liability as an Insurance Market, 14 J. LEGAL STUd. 645 (1985). 


\section{B. Damages}

There is no reason to believe that the optimal system of compensation is one that leaves a prospective patient wholly indifferent (assuming that money could ever make him so) between the successful provision of services and the specified compensation. Although that objective for contract damages has often been defended on justice grounds, ${ }^{15}$ the standard is not applicable to all personal injury cases, but only to so-called "stranger" cases-that is where the parties (for example, drivers encountering each other involuntarily on the road) have had no opportunity to negotiate an allocation of risks. The case of medical malpractice, arising as it does out of a contract situation, is completely different. Here, abstract symmetry is not the test of a sound damage rule. Instead, the objective should be the maximization of the expected joint profit of the two parties, and it is just that standard that tort law's requirement of full compensation must satisfy before it should be regarded as the optimal legal rule. ${ }^{16}$

In many contexts, full compensation will not prove ideal. To return again to industrial accidents, one essential component of the voluntary plans (like the modern mandatory statutes) was damage awards that provided a maintenance allowance but not the full monetary equivalent for the worker's loss. In principle, if there were no alternative way to monitor the employer's behavior and no need to monitor the worker's conduct, then full damages for compensable events would provide the correct incentives for the employer while leaving the plaintiff with the constant income flow. But these assumptions are not plausible in either regulated or unregulated markets.

First, the individual worker does have some control over the occurrence of injury, so that in the absence of an effective contributory negligence defense, the desired incentives can be restored in part by limiting the worker's potential recovery so that he is not indifferent to the occurrence of injury. Full compensation, on the other hand, creates the incentive problem that economists call "moral hazard," which can increase the incidence of injury.

Second, as huge sums are at stake, full compensation tends to magnify the consequences of error in the determination of whether an injury was in fact covered. Lower damage payments could reduce these costs to an acceptable level.

Third, reductions in award levels could reduce the litigation costs in the event of trial. In the usual models of litigation, the two parties combined will not expend in litigation sums that exceed the difference between their respective assessments of the plaintiff's expected recovery. ${ }^{17}$ Thus, if the

15. The classic defense is still Fuller \& Perdue, The Reliance Interest in Contract Damages (pts. 1 \& 2), 46 Y ALE L.J. 52, 373 (1936-1937).

16. For a formal analysis, see Graham \& Peirce, Contingent Damages for Product Liability, $13 \mathrm{~J}$. Legal Stud. 441 (1984); Shavell, Damage Measures for Breach of Contract, 11 Bell J. Econ. 466 (1980).

17. "Under the American system, there will be a trial if and only if the plaintiffs estimate of the expected judgment exceeds the defendant's estimate by at least the sum of their legal costs." Shavell, Suit, Settlement, and Trial: A Theoretical Analysis Under Alternative Methods, 11 J. LEGAL STUD. 55, 63 (1982) (italics omitted). 
plaintiff thinks that the case is worth $\$ 100$ and the defendant thinks it is worth $\$ 60$, total litigation expenses will not exceed $\$ 40$, because if they did, then both parties could be better off with a settlement anywhere within the $\$ 60$ to $\$ 100$ range. Reducing the stakes should reduce the differences between the parties' expectations in litigation, thus increasing the likelihood of settlement and decreasing the total amounts spent on litigation.

Fourth, because individual workers often have other forms of insurance against the loss, complete coverage would result in overinsurance, increasing administrative costs and the costs associated with moral hazard. ${ }^{18}$

Many of these same considerations arise in medical cases, where again there is no reason to believe that the principle of full compensation, though currently established in law, represents the preferred contractual solution. Although it is undoubtedly less of a concern here than in the case of industrial accidents, controlling patients' risk enhancing conduct is one issue. For physicians paid on a fee-for-service basis, the concern is not with patients who engage in risky or unwise conduct before seeking medical care. Such patients must expect to pay higher bills for more extensive medical attention and presumably also for the greater risk that their treatment will result in an injury giving rise to a malpractice claim. Even in the fee-for-service market, however, there is still the concern that the heavily insured patient will not follow medical instructions after receiving treatment. Although the contributory negligence defense remains available in principle to handle these cases, as does a remoteness-of-damage argument (the excessive eating, not the bad treatment, caused the injury), these defenses may be difficult to prove even when they are applicable. On the other hand, monetary limitations on the potential recovery would work the considerations into the system automatically, just as these limitations do in workers' compensation.

The size of the stakes seems to work the same way in the industrial and medical areas. In medical cases, high stakes increase the consequences of error in fact-finding and raise the costs of litigation. Both types of cost could be reduced by limiting compensation levels. These same problems reveal why there is reason to be concerned about the patient's collateral benefits from health, life, and disability insurance. A private agreement aimed at reducing the stakes without impairing essential financial protection could easily provide for a complete or partial offset against awarded damages of the proceeds from collateral sources. It seems likely that tort law's expectation measure of damages would not be chosen by patients and providers freely contracting about prospective liability for medical injuries.

\section{Procedure}

The present malpractice insurance system incurs more costs in evaluating claims than in paying them, ${ }^{19}$ and the largest administrative costs are incurred

18. See Danzon, Tort Reform and the Role of Government in Private Insurance Markets, 13 J. LEGAL STUd. 517, $517-27$ (1984).

19. P. Danzon, Medical Malpractice: Theory, Evidence, and Public Policy 187 (1985). 
in litigating a relatively small number of claims and in preparing for such litigation. Some of these costs may be avoidable by recourse to arbitration. The use of private arbitration was a common feature of early voluntary workers' compensation plans, and there is no obvious reason why it would not similarly be employed in the medical area. Although access to the court system gives plaintiffs certain strategic advantages, both parties stand to gain if overall litigation costs can be reduced. Because arbitration, agreed to before the occurrence of an injury, could reduce these costs without reducing the reliability of the ultimate decision, it seems highly likely that even if tort liability and tort damage rules were retained in toto, under contract arbitration will be a fairly popular option.

\section{IV}

\section{Contract and the Structure of the Firm}

There is still one piece missing from the puzzle. The preceding discussion has considered the contractual changes in the rules governing medical malpractice that might occur within the traditional institutional structure of medicine. There is reason to believe, however, that resort to contractual schemes may be easier for HMO's and other innovative health care plans. ${ }^{20}$ These firms may have other advantages in dealing with the problem of medical accidents. If so, movement in the direction of contractual specification of rights may presage a further shift away from fee-for-service care and toward prepayment plans such as HMO's.

It is instructive on this point to note that the voluntary workers' compensation plans were not adopted by all firms but only by those that were able to bear the front-end cost of putting a novel contractual system into place. Likewise, individual physicians, who are not able to cope well with the modern medical malpractice system, may also be at a systematic disadvantage in a world in which contracting is freely allowed. Lacking economies of scale for developing innovative programs and in negotiating with patients, they may be forced by circumstances to continue operating within the dysfunctional tort system except to the extent they can obtain legislative relief by collective political action. HMO's, on the other hand, can negotiate master contracts with employers or unions that represent the consumer's interest and need not bear the cost of educating or negotiating with individual patients. Even where there are individual enrollments, an economy of scale lies with the firm that can spread the start-up costs over a larger number of cases. Although profession-sponsored educational campaigns and form contracts

20. A similar point is made id. at 211: "However, the feasibility of a contract approach to malpractice liability is becoming much stronger as the traditional fee-for-service system with unrestricted choice of providers breaks up under pressures for cost containment." The key element here is that the use of responsible intermediaries, analogous to brokers and agents, is a cost effective way to overcome various informational and transactional barriers. I missed this important point in earlier writings on the subject. See, e.g., Epstein, Contracting Out of the Medical Malpractice Crisis, 20 PERSP. Biology \& Med. 228, 238 (1977). The ability to vary firm structures to take into account malpractice risk strengthens the case for contract solutions. 
may help, individual physicians would appear to be at a significant competitive disadvantage.

The HMO's may have other advantages as well. They are in a position to monitor their physicians and to ensure that they meet the required standard of care. This in turn should reduce the frequency of instances of medical malpractice. Their patients, recognizing the administrative controls that are in place and the plans' reputational interest in providing good care, may be more willing than patients of solo practitioners to forego the threat of malpractice actions. Consumers may perceive that less deterrence is needed where administrative oversight is present than where an individual physician must police his own work. The HMO's could more easily demonstrate the effectiveness of their internal monitoring to their insurers, and then pass on a portion of their reduced premiums to customers in the form of lower charges.

HMO's should also have an advantage in dealing with medical malpractice situations because they can handle them within the firm. One common remedy in ordinary contracts cases calls for the contractor (say a roofer) to repair or replace the damaged work. Such remedies could carry over, at least informally, into medical areas. Thus, a fee-for-service physician who mistreats a patient may be in a poor position to fix the damage himself and reluctant to employ another physician to do so. An HMO, on the other hand, is already obligated to treat the patient and has numerous physicians capable of doing so, at no extra cost to the patient. In effect, there is an element of automatic coinsurance, inducing the firm to do the work correctly the first time and to minimize any damage that results. Finally, whereas fee-for-service providers are said often to invite malpractice actions through poor customer relations (for example, sending a large bill for a botched procedure), HMO's are able to respond to customer complaints in an organized fashion and even to employ specialists in mediation and customer relations.

\section{CONCLUSION}

This article has canvassed many reasons why a world of competitive markets and voluntary contracts should result in the development of new liability rules that respond to the problem of imperfect information in medical care better than traditional tort rules. In part by drawing the parallel to the early responses by the private sector to the problem of industrial accidents, it has been shown that there is nothing special, much less sacred, about medical services that justifies exempting them from ordinary contracting processes. Properly viewed, there are enormous opportunities for joint gains from voluntary institutional arrangements. Although speculating on precisely what private contracts allocating medical risks will look like is hazardous, it seems clear that the standard contract terms imposed by courts and legislatures can be substantially improved upon.

Kenneth Arrow has noted that "strong insistence upon the fee-for-service model" was one factor that prevented the realization of effective competition 
in markets for medical services. ${ }^{21}$ The rise of HMO's and other market developments in recent years have helped to change that situation. If, as suggested herein, HMO's and other innovative health care arrangements are better equipped to deal with the risks posed by malpractice, then we should expect their continued expansion. This trend may continue, of course, whether or not the current restrictions on contractual freedom are relaxed by the legal system, but the success of these private innovations, based on new types of contractual relationships, suggests that contractual freedom leads to the provision of better medical care. Letting private parties contractually address the malpractice problem should be equally beneficial.

21. See Arrow, Uncertainty and the Welfare Economics of Medical Care, 53 Am. Econ. Rev. 941, 948-54 (1963). Among the other factors, Arrow notes that the demand for medical services is not steady, that it is difficult to test the product before its consumption, that there is uncertainty in the administration of care and the outcome of disease, and that there are restrictions on the supply side. HMO's seem to respond to these problems as well. Once there is a firm that supplies medical services, there is greater regularity in the payment for services, a greater ability to judge the quality of the services in question, and, of course, a greater ability to adopt alternative administrative modes to handle the liability problems. 